\title{
Biosensors for the assessment of fish health: a review
}

\author{
Hideaki Endo ${ }^{1} \cdot$ Haiyun $\mathrm{Wu}^{1}$
}

Received: 7 March 2019 / Accepted: 1 April 2019 / Published online: 2 May 2019

(c) The Author(s) 2019

\begin{abstract}
Methods that can be used to check the health of fish, determine their physiological condition and detect abnormalities at an early stage, have been attracting recent attention. The health of fish can be determined by the assessment of stress responses, prediction of spawning time, and highly sensitive detection of bacteria that cause diseases in fish, etc. However, it can be difficult to accurately measure these parameters due to factors such as sampling errors, uncontrollable aquaculture conditions and unsound methodological approaches. Also, the methods currently used are time-consuming and may involve complicated processes. Thus, there is a high demand for novel approaches for the assessment of fish health. We have thus focused on the development of a biosensor to measure target factors of fish health by combining biocatalytics and electronics technology. We believe that this technology can greatly improve the assessment of the health of fish produced for consumption. In this article, we described various biosensors that can both rapidly and easily measure indicators of fish health. Future applications of these techniques are also discussed.
\end{abstract}

Keywords Stress monitoring · Spawning prediction · Pathogenic bacteria detection $\cdot$ Health control $\cdot$ Physiology $\cdot$ Living environment $\cdot$ Carbon nanotube $\cdot 17,20 \beta$-dihydroxy-4-pregnen-3-one

\section{Introduction}

The dependence on aquaculture for the production of many fish species is increasing worldwide due to declines in traditional fishing industries as a result of increased costs and stricter international regulations (Frankic and Hershner 2003; Asche and Tveterås 2005). The safety and quality of breeding fish as an important food source are therefore of critical importance in aquaculture (Anderson 2002). In aquaculture, a high density of fish is often maintained in a single pond to increase production efficiency. However, a high density of fish can lead to a deterioration of water quality due to the accumulation of residual bait and excrement, which induces stress and lowers immunity in fish, thereby

Published with support by the Japan Society for the Promotion of Science (JSPS) KAKENHI Grant no. JP 262003.

Hideaki Endo

endo@kaiyodai.ac.jp

Haiyun $\mathrm{Wu}$

wuhaiyun@kaiyodai.ac.jp

1 Graduate School of Marine Science and Technology, Tokyo University of Marine Science and Technology, 4-5-7, Konan, Minato-ku, Tokyo 108-8477, Japan increasing their susceptibility to illness (Naylor et al. 2000; Stentiford et al. 2012). Diseases in farmed fish are generally treated by the administration of drugs such as antibiotics, but there are concerns regarding residues of these drugs in fish. New aquaculture techniques that do not rely on antibacterial agents are required for both the health of consumers and the sustainable development of the aquaculture industry (Cabello 2006; Baquero et al. 2008). For this reason, health checks on fish farms are necessary to regularly evaluate fish health and detect abnormalities and disease at an early stage. Thus, the development of an inspection system for the rapid and easy evaluation of fish health is in high demand.

\section{Fish health determination}

Recent studies have revealed that the blood glucose concentration in fish varies according to the level of stress; this concentration can reflect breathing disorders and nutritional status, which can be used as indicators of fish health (Fletcher 1984). A decrease in the total blood cholesterol concentration is also an important indicator of the ability of fish to fight bacterial infections (Maita et al. 1998a, b). In addition, changes in cortisol and lactic acid concentrations 
are important indicators of fish stress (Fromm 1980; Pickering and Pottinger 1989a, b). These measurements are conventionally performed using clinical test kits designed for use in humans and require complicated operations, such as fish capture, blood collection and processing, and measurement of samples by absorption spectrometry (Wells and Pankhurst 1999).

A quick and easy method for predicting the timing of ovulation for the efficient collection of fish eggs is also needed. Fish maturation and ovulation are greatly influenced by various environmental and physiological factors, making it difficult to accurately predict the timing of ovulation (Stagey et al. 1979; Zeilinger et al. 2009). Blood concentrations of the maturation-inducing hormone 17,20ß-dihydroxy-4pregnen-3-one (DHP) rapidly increase during the egg maturation stage. Accurate detection of DHP concentrations would enable the prediction of ovulation in fish (Stacey et al. 1989). Current detection methods used to quantify steroidal hormones, including those using DHP, include liquid chromatography and fluorescence detection (Inoue et al. 2002; Tschmelak et al. 2004), both of which are complicated and time-consuming.

Furthermore, the detection of pathogenic bacteria in fish is important in the modern aquaculture industry (Irianto and Austin 2002). Rapid detection methods such as flow cytometry (FCM) and polymerase chain reaction (PCR) were recently developed to identify and measure pathogenic bacteria in fish (Chilmonczyk and Monge 1999; González et al. 2004). An extremely low number of bacterial cells in samples, however, decreases the probability of detection. The presence of contaminants other than bacterial bodies in samples also hinders bacterial detection.

\section{Biosensors for evaluating fish health}

The research and development of biosensors to evaluate the functions of living organisms using electronics technology is currently vigorously promoted. Advances in electronics technology allow for the measurement and detection of specific substances, even in a complex environment (Yogeswaran and Chen 2008; Windmiller and Wang 2013). Biosensors take advantage of molecular elements of biological processes such as enzymes and antibodies to identify target substances. When biocatalysts react with a target substance, they can serve as discriminating elements that can cause minor changes in parameters such as current, resistance, and heat due to the generation and consumption of chemical substances (Fig. 1). Biosensors can measure specific target substances easily and rapidly by detecting these small changes using signal conversion elements such as electrodes and optical devices, which transform the changes into electric signals

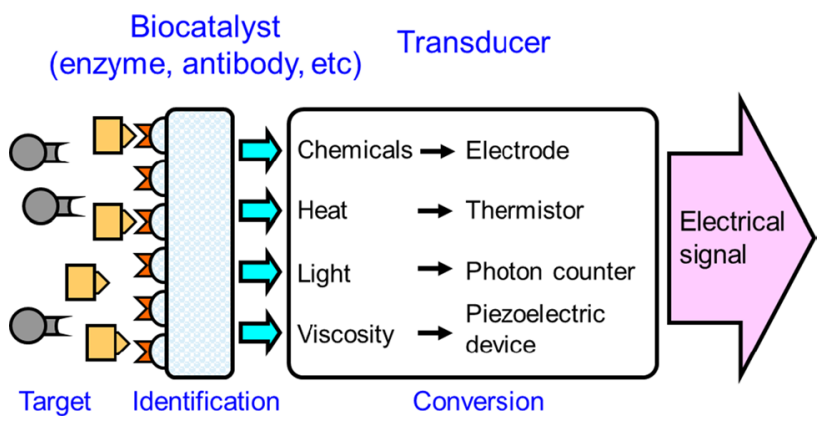

Fig. 1 Principles of a biosensor

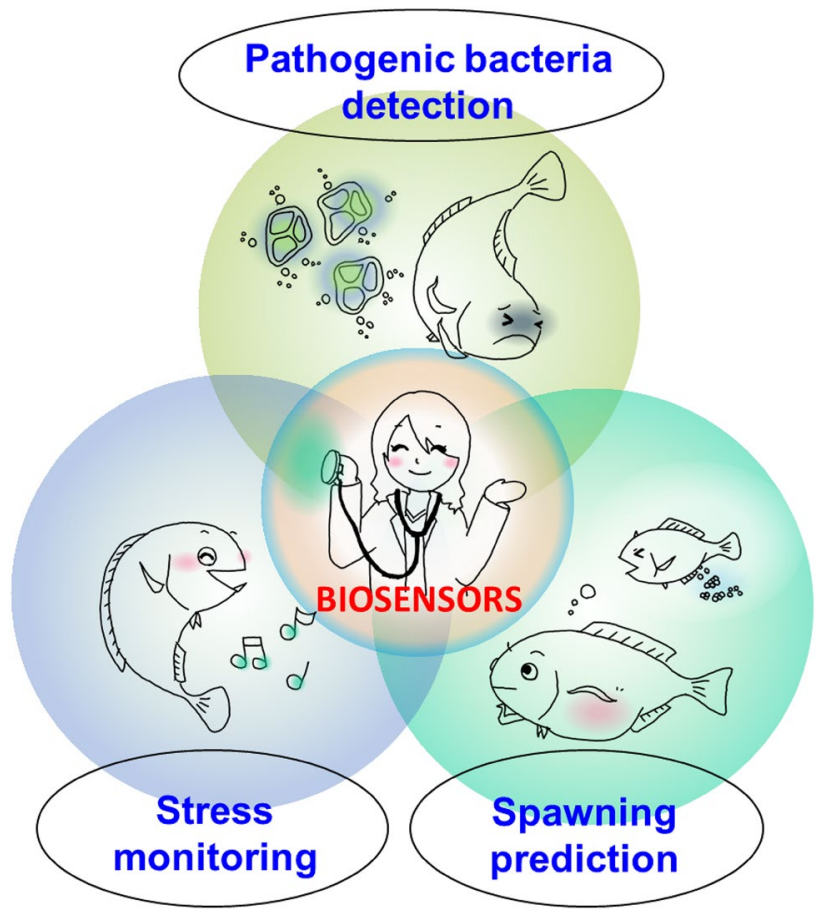

Fig. 2 Types of fish health checks that can be achieved with biosensors

(Grieshaber et al. 2008). Due to their high sensitivity and specificity, biosensors are currently being developed to evaluate fish health.

Over the last few decades, researchers have developed and applied biosensor technology to determine fish health and establish new diagnostic methods that can greatly contribute to its improvement. In an effort to improve the safety of cultured fish on the market, various types of biosensors for fish health checks have been developed. In this paper, we review some biosensor systems for the measurement of blood components, prediction of ovulation time, and detection of pathogenic bacteria in fish, all of which are considered particularly important parameters of fish health (Fig. 2). 


\section{Monitoring stress responses}

In human health checks, blood components are indispensable as parameters for measurement. Similarly, in fish, concentrations of blood components also indicate health to some extent. For example, recent studies revealed that changes in blood cortisol and glucose concentrations reflect the degree of fish stress, respiratory disorders, and nutritional status (Rotllant and Tort 1997; Barton 2000). In general, physiological stress in fish induces a primary response consisting of concentration changes of hormones, such as cortisol and catecholamine, followed by a secondary response, consisting of a change in the blood glucose concentration caused by metabolic activation of the stress hormones (Mazeaud et al. 1977). Factors that contribute to the stress response include: physical factors such as flow velocity, temperature, and contact; chemical factors such as ammonia, nitrous acid, and poisons; and behavioral factors, such as the threat of predation, social activities of fish, and territorial behavior (Bonga 1997; Gilmour et al. 2005). In recent stress-response studies, a change in the concentration of cortisol or glucose was commonly used as an indicator. Because most of these substances are measured by applying human clinical test kits, blood extraction of captured fish has to be performed outside the aquatic environment (Lowe et al. 1993). These operations in themselves are stressful for fish.

Cortisol as a biomarker of the stress response in fish has been well studied (Pickering and Pottinger 1989a, b). Cortisol stimulates glucose production through gluconeogenesis, which increases the plasma glucose concentration. Pottinger and Carrick (2001) described the plasma cortisol profiles and physiological effects in response to various stressors in fish. Electrochemical immunoassays are highly sensitive, inexpensive methods for evaluating biochemistry, and we developed these types of biosensor systems to rapidly and easily measure fish cortisol levels (Muramatsu et al. 2011; Wu et al. 2015a, 2016, 2017a).

Recently, we developed a new methodological approach using glucose oxidase (Gox) as a signal amplifier (changes on the electrode surface due to the formation of the antigen-antibody complex) to reliably detect a wider range of plasma cortisol levels in fish, as shown in Fig. $3(\mathrm{Wu}$ et al. 2017b). Formation of the antibody-antigen complex by a simple one-step immunoreaction (Fig. 3a) between the immobilized anti-cortisol antibody and cortisol in the sample solution introduces a barrier against direct electrical transmission between the immobilized Gox and the electrode surface. Due to the barrier effect, the output current decreases as a response of the biosensor through amperometry, as shown in Fig. 3b. Because this response is proportional to the cortisol concentration, we
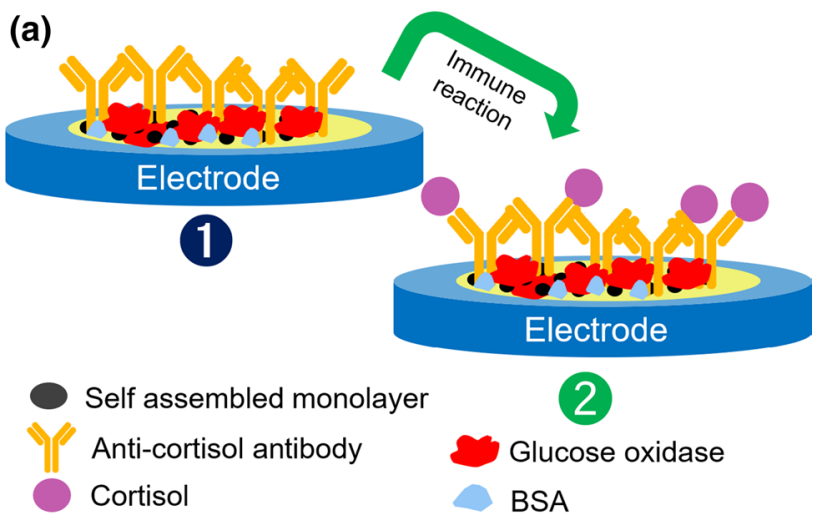

(b)

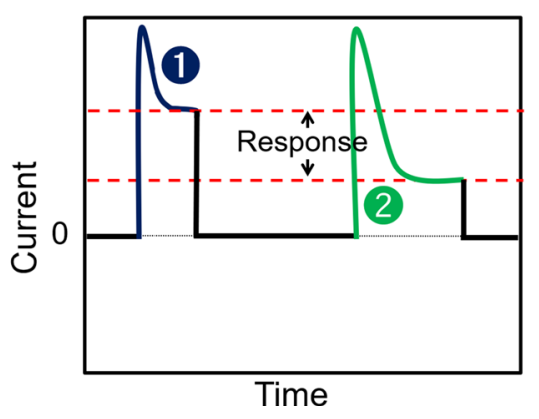

Fig. 3 Measurement basis of the cortisol biosensor. a Formation of the antibody-antigen complex. b Response of the biosensor using amperometry

can easily calculate the concentration of cortisol through the response of the sensor. The calibration curve showed a good linear relationship between the rate of decrease in the output current and the logarithm of cortisol concentration in standard cortisol solutions ranging from 1.25 to $200 \mathrm{ng} \mathrm{ml}^{-1}$. Cortisol levels in unstressed fish and stressed fish (Fig. 4) could also be measured individually by both the proposed and conventional methods. The data obtained with the sensor system strongly correlated with the data obtained using the enzyme-linked immunosorbent assay (ELISA) method in the range of $17.30-183.93 \mathrm{ng} \mathrm{ml}^{-1}$ (correlation coefficient: 0.962; Fig. 4). Because fish behavior is similar in response to different stressors (e.g. swimming to the surface for fresh air and rapid escape, etc.), it is difficult to know which factors contribute to increased stress, although stress levels are indicated by cortisol levels. Our proposed biosensor system simply and quickly showed the following approximate order of impact of acute fish stressors: air exposure $>$ light stimulation $>$ nitrite addition $>$ unstressed. Elucidating the approximate order of the impact stressors may help to clarify which stressor is contributing to an increase in cortisol level in fish, which is a good indicator of acute stress. The range of the cortisol level in fish plasma ranges from dozens to hundreds of nanograms per milliliter. Therefore, given the 


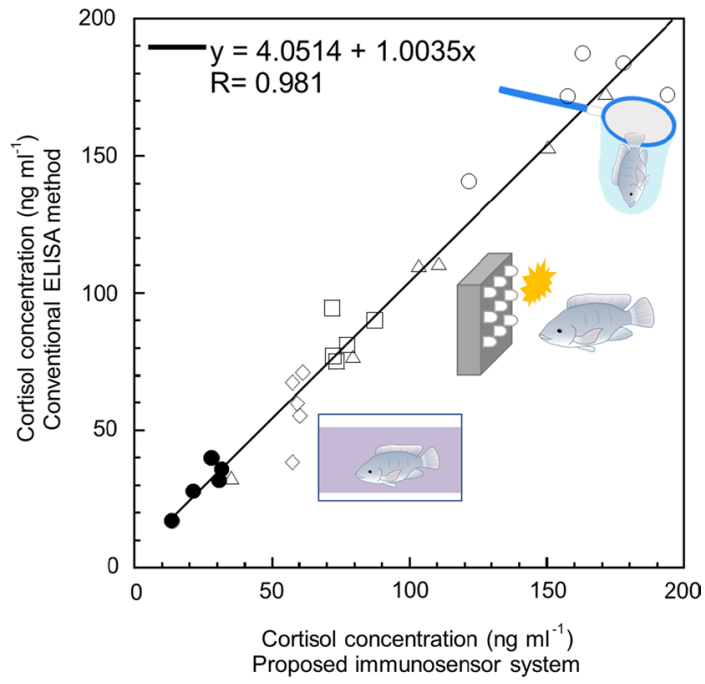

Fig. 4 Correlation between data obtained with the biosensor system and the enzyme-linked immunosorbent assay method. Filled circle Unstressed, circle air exposure, square light stimulation, diamond nitrite exposure, triangle interaction with other fish (Modified from Fig. 6b, Wu et al. (2017b) New approach for monitoring fish stress: a novel enzyme-functionalized label-free immunosensor system for detecting cortisol levels in fish. Biosens Bioelectron 93: 57-64)

calibration range of the sensor system, plasma samples do not need to be further diluted and can be measured directly in most cases. Also, measurement using the proposed sensor requires only $\sim 30$ min per sample, including the immunoreaction time. The measurement is also achieved with amperometry, increasing the simplicity and rapidity of detection. Amperometry can be easily performed, and in the future this system may be a potential foundation for in vivo or point-of-care measurements. We believe the electrochemical basis of the proposed biosensor can also be used to design a portable device that can be used in fieldwork.

Many different factors are considered to be stressors in fish. Deterioration of water quality, such as increasing levels of ammonia, might result in chemically induced stress. Moreover, social conflict in fish causes a fight-or-flight response and affects various stress responses that impair fish health. Fish such as Nile tilapia (Oreochromis niloticus) and rainbow trout (Oncorhynchus mykiss) are particularly influenced by social stress when housed in a water tank (Bonga 1997). These factors have long-term effects, so the stress response may vary over the long term and is closely related to some other indicators of fish health.

In contrast to cortisol, glucose varies in response to stress but returns to normal values within $24 \mathrm{~h}$ (Silbergeld 1974). These substances are measured using chemical methods, which are inexpensive and easy to perform. For rapid and simple determination of glucose concentrations in fish blood, we developed a needle-type biosensor system (Endo

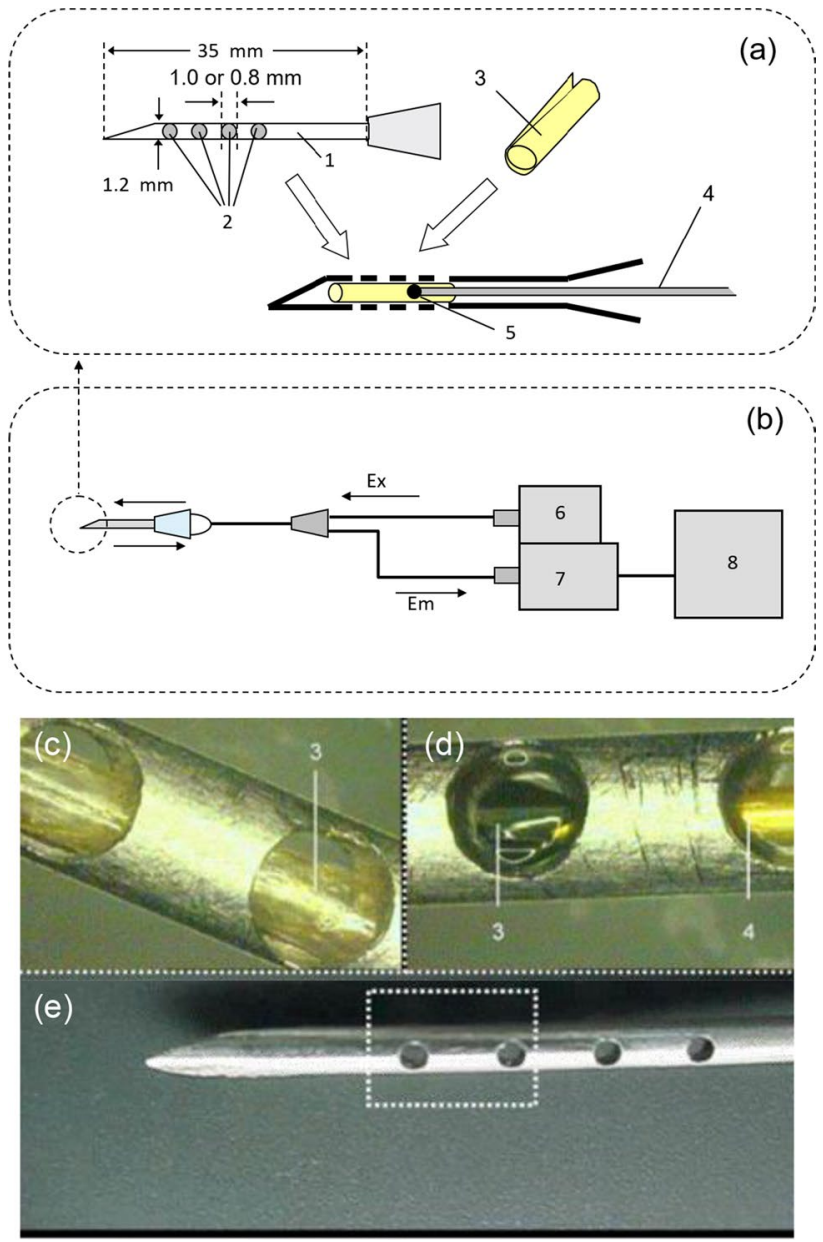

Fig. 5 Schematic diagram of the needle-type enzyme sensor system $(\mathbf{a}, \mathbf{b})$ and images of the detector region $(\mathbf{c}-\mathbf{e})$. 1 Needle-type hollow container, 2 round holes, 3 immobilized enzyme membrane, 4 optical fiber probe, 5 ruthenium complex, 6 excitation light source, 7 spectrometer, 8 personal computer [Modified from Fig. 1, Endo et al. (2006) A needle-type optical enzyme sensor system for determining glucose concentrations in fish blood. Anal Chim Acta 573-574: 117-124]

et al. 2006). The sensor comprises a hollow needle-type container (18-gauge needle), immobilized enzyme membrane, and optical oxygen fiber probe with a ruthenium complex (Fig. 5). The enzyme membrane was prepared from Gox, an azide-unit pendant water-soluble photopolymer, and an ultra-thin dialysis membrane. The optical fiber probe comprises a thin layer of hydrophobic sol-gel material at the distal end and a sol-gel matrix containing ruthenium complex at the tip. Exposure to light activates the ruthenium complex in the probe tip, causing it to fluoresce with an emission wavelength of $600 \mathrm{~nm}$. When an oxygen molecule is in the vicinity of the excited ruthenium complex, the excess energy is non-radioactively transferred to the oxygen molecule, and the fluorescence signal is thereby quenched. Thus, the changes in the intensity of the fluorescence reflect the 
amount of dissolved oxygen in the hollow needle-type container. The sensor, which is inserted into the caudal vein of the fish, measures changes in the concentration of dissolved oxygen inside the hollow container due to oxidization by Gox according to the following formula:

D-glucose $+\mathrm{O}_{2} \stackrel{\text { Gox }}{\longrightarrow}$ D-gluconolactone $+\mathrm{H}_{2} \mathrm{O}_{2}$

We inserted the sensor into test fish (Nile tilapia O. niloticus) to measure blood glucose concentrations. The sensor responded immediately after insertion allowing glucose concentration change to be monitored. Good correlations were observed between values determined using the sensor and conventional methods in the range of $48-157 \mathrm{mg} \mathrm{dl}^{-1}$ (correlation coefficient, 0.9474). Blood glucose concentrations were measured by immobilizing each fish for about $3 \mathrm{~min}$. Once the test is complete, the fish are returned to the same water tank, and the sensor cleaned with a buffer solution. Good reproducibility was observed over 60 measurements without exchange of the enzyme membrane.

Capture of the fish from the water tank using a net so that blood samples can be obtained for each measurement may cause some unnecessary stress to fish. Because the glucose concentrations in fish change in accordance with their stress response, real time measurement is highly desirable. It is thus difficult to say whether the above sensor system is the best way to measure the stress response. Further, it is difficult to measure blood components in real time because the sensor output decreases over time due to blood coagulation and protein (e.g., albumin, $\gamma$-globulin) coalescing on the sensor. In general, when measuring blood components in fish and other animals like humans, the sensor is inserted into a blood vessel, blood clotting occurs due to the action of coagulation factors such as fibrinogen in the blood as the sensor indwell time elapses, and the performance of the sensor is notable decreased as a consequence (Endo et al. 2006). In summary, a minimally invasive sensor system to evaluate fish, and a solution that addresses the problem of sensor obstruction in the blood, is desired.

To address these problems, we developed some novel wireless biosensor systems to monitor the glucose concentrations in fish (Endo et al. 2009a, 2010). This type of sensor system for fish is unprecedented, and can obtain real time measurements of blood glucose concentrations even while test fish swim freely (Fig. 6). The sensor is based on a microelectrode composed of platinum-iridium wire and silver/silver chloride paste; Gox is immobilized on the detection part of the electrode. The glucose concentration can be determined by measuring the change in the amount of hydrogen peroxide generated when the Gox and glucose as a substrate undergo an enzymatic reaction on the electrode, as in the formula above. By connecting this sensor to a waterproof wireless potentiostat, the glucose concentration can be monitored in real time by transmitting the output current value of the sensor to land by radio waves. For the sensor insertion site, we focused on the eyeball interstitial sclera fluid (EISF), the interstitial fluid inside the outer membrane of the fish eyeball. There was a good correlation between the glucose concentration in the EISF and that in the blood (Yonemori et al. 2009; Endo et al. 2009a). Furthermore, because the EISF does not contain coagulation factors as in blood, its characteristics can be maintained for a long time even after the sensor is inserted. We also introduced some functional components such as an electron mediator (Takase et al. 2012a), a highly conductive material (Takase et al. 2012b) and biocompatible polymer (Takase et al. 2013) to improve the performance of the biosensor. Some experiments were conducted based on previous experience. We used this wireless biosensor system as a new approach for monitoring "actual stress" in real time induced by various stress factors experienced by fish (Wu et al. 2015b). Real time blood glucose levels were monitored in free-swimming fish exposed to various chemicals and other stressors to evaluate the physiological state induced by each stressor and to elucidate how the stress factors affected behavior. In the first experiment, we tested the fish response to ammonia, nitrite, and nitrate separately with the same reagent concentration $\left(25 \mathrm{mg} \mathrm{l}^{-1}\right)$. Two water tanks were prepared with either normal breeding water $(\alpha)$ or with reagent added up to a concentration of $25 \mathrm{mg} \mathrm{l}^{-1}(\beta)$. Fish were first acclimated to normal breeding water in water tank $\alpha$ for more than $15 \mathrm{~h}$. After confirming that the sensor output current had stabilized, the fish were transferred to water tank $\beta$, and the glucose levels were monitored. Under natural conditions, the ammonia-nitrogen concentration increases in the water due to fish waste, the accumulation of dead organisms, and other debris from anthropogenic sources such as industry and agriculture. In fish, short-term exposure to an elevated ammonia concentration leads to increased gill ventilation, erratic and quick movements, discontinuation of foraging, and mortality. The accumulation of nitrite as an intermediate product between the conversion of ammonia to nitrate is also toxic to fish, and the effects of chronic exposure vary with body size, species' tolerances, and other water quality variables (Lewis and Morris 1986). In this experiment, the ammonia and nitrite had strong stress-inducing effects (Fig. 7a, b). Although nitrate can also affect fish gas exchange, it is not as likely as ammonia and nitrite to induce stress in fish (Fig. 7c). Our sensor allowed us to detect not only the reaction of the fish to such chemicals over a period of time, but also to obtain real time data, which was not previously possible using conventional methods.

Using this biosensor, we also tried to elucidate the relationship between threatening behaviors among fish and the stress response (Wu et al. 2015b). When Nile tilapia males 
Fig. 6 Schematic diagram of the wireless biosensor system for fish. 1 Needle-type enzyme sensor, 2 waterproof sheet, 3 wireless potentiostat, 4 nylon threads, 5 receiver, 6 personal computer, 7 test fish (Nile tilapia Oreochromis niloticus) [Reproduced from Fig. 1, Endo et al. (2009a) Wireless enzyme sensor system for real time monitoring of blood glucose concentrations in fish. Biosens Bioelectron 24: 1417-1423]

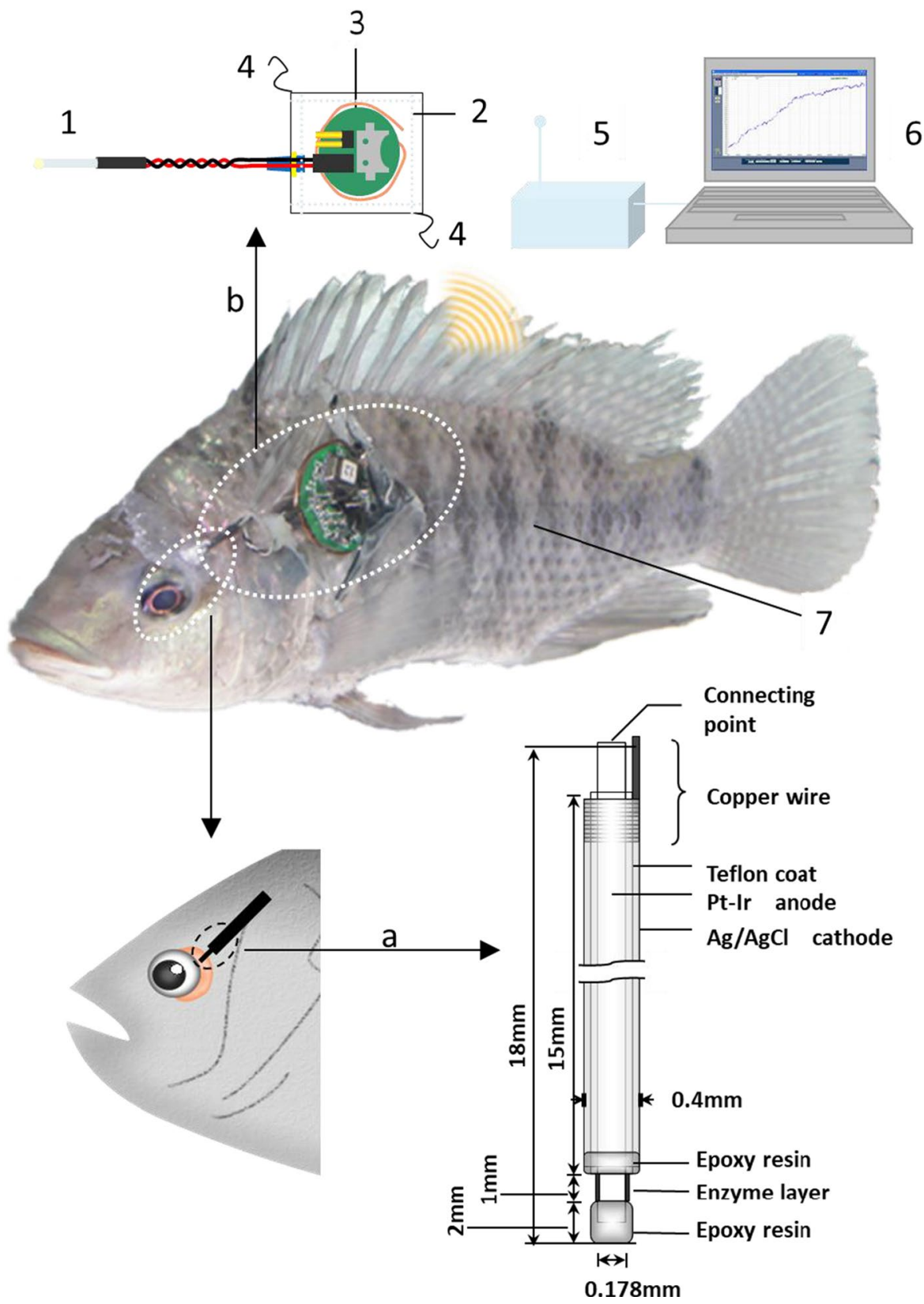

exhibit threatening behavior towards conspecific males, stress is thought to be experienced by the fish, but the actual stress factor is not clear. Therefore, we attempted to find traces of the stress response in small male fish. The results are shown in Fig. 8. Before the experiment, medium-sized tilapia swam alone in the water tank. First, a smaller tilapia was placed into a water tank in which a medium-sized tilapia equipped with a sensor was swimming; after mixing of fish for a certain period, the smaller fish was removed from the water tank. Next, after leaving the medium-sized tilapia to swim alone for 1 night to ensure that the stress response value had become constant, a large tilapia-much larger than the medium-sized tilapia-was placed into the water tank. After mixing of fish for a certain period, the larger fish was removed from the water tank. When a small tilapia was introduced, the glucose concentration of the medium-sized tilapia hardly changed. This suggests that the presence of the small tilapia induces little stress in the medium-sized tilapia. Next, when the large tilapia was introduced, the glucose concentration of the medium-sized tilapia increased remarkably. It is assumed that the medium-sized tilapia was under high stress when chased by the large tilapia. Our sensor system allowed us to monitor the stress response during the fish territorial dispute in real time, and to elucidate the relationship between threatening behavior and the stress response. 

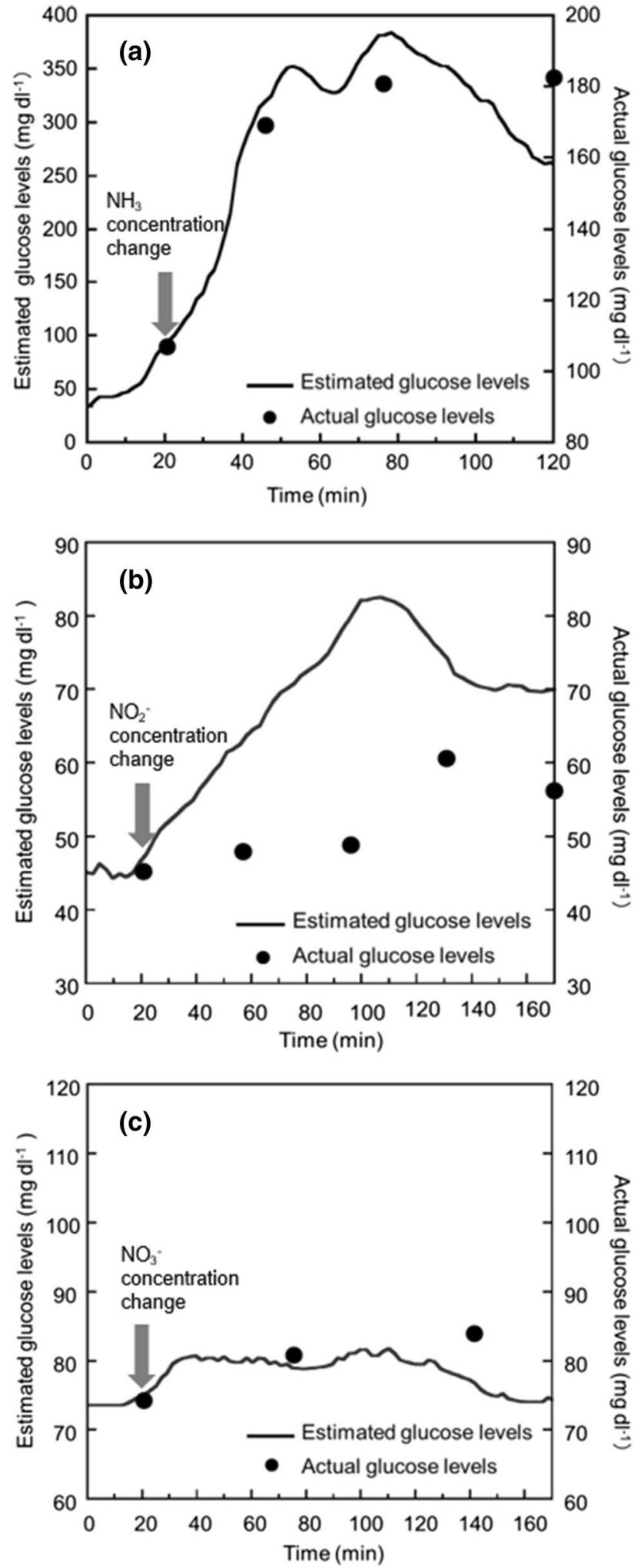

Fig. 7 Stress monitoring of the effects of change in the concentration of ammonia-nitrogen compounds. Glucose concentrations (black circles) were used for the one-point calibration method. a Ammonia concentration changed from 0.25 to $25 \mathrm{mg} \mathrm{l}^{-1}$. b Nitrite concentration changed from 0 to $25 \mathrm{mg} \mathrm{l}^{-1}$. c Nitrate concentration changed from 0 to $25 \mathrm{mg}^{-1}$ [Reproduced from Fig. 5, Wu et al. (2015b) Fish stress becomes visible: a new attempt to use a biosensor for real time monitoring of fish stress. Biosens Bioelectron 67: 503-510]

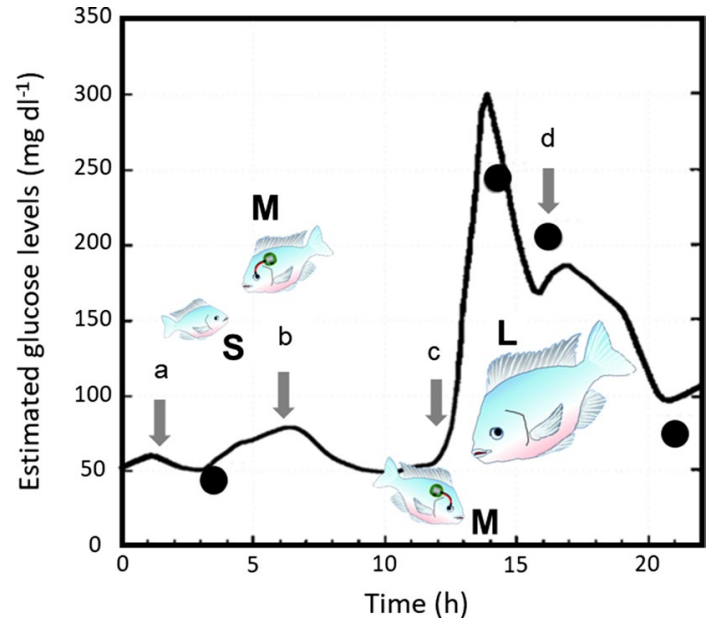

Fig. 8 Monitoring of the effects of stress on fish behavior in interactions between individual fish. The curve shows the change of glucose concentration of the medium-sized tilapia $(M)$. a The small tilapia $(S)$ was placed into the water tank, then $\mathbf{b}$ removed from the water tank. c A large tilapia $(L)$ was placed into the water tank, then $\mathbf{d}$ removed from the water tank. Glucose concentrations in the blood $3.5 \mathrm{~h}$ (black circles) were used for the one-point calibration method [Modified from Fig. 6a, Wu et al. (2015b) Fish stress becomes visible: a new attempt to use a biosensor for real time monitoring of fish stress. Biosens Bioelectron 67: 503-510]

\section{Estimation of spawning time}

In aquaculture, importance is placed on ensuring the systematic production of stable and high-quality fish eggs immediately after ovulation to enable fish culture (Matsuyama et al. 1991). The establishment of a quick and easy method for predicting the timing of ovulation is needed to reduce work in fish farms and to efficiently collect eggs. Generally, maturation and ovulation of fish are greatly influenced by various environmental and physiological factors, so it is difficult to accurately predict the timing of ovulation. Under these circumstances, DHP, a hormone that rapidly increases in the blood at the egg maturation stage, may help us to predict ovulation (Young et al. 1983; Lou et al. 1984). Methods such as liquid chromatography and fluorescence detection are usually used for the quantification of steroidal hormones including DHP, but these methods require complicated and time-consuming procedures. Biosensor systems for the measurement of DHP were developed in our lab for rapid and easy estimation of the timing of spawning (Endo et al. 2012; Hirai et al. 2013).

Figure 9 shows the basis on measurements for our first DHP biosensor (Endo et al. 2012). This system is based on the principle of quantifying DHP by analyzing the current change on the electrode surface during the reaction of DHP and anti-DHP antibody using cyclic voltammetry (CV). We measured the electrical current, which changed according to the progression of immunoreactions on an $\mathrm{Au}$ 
(a)
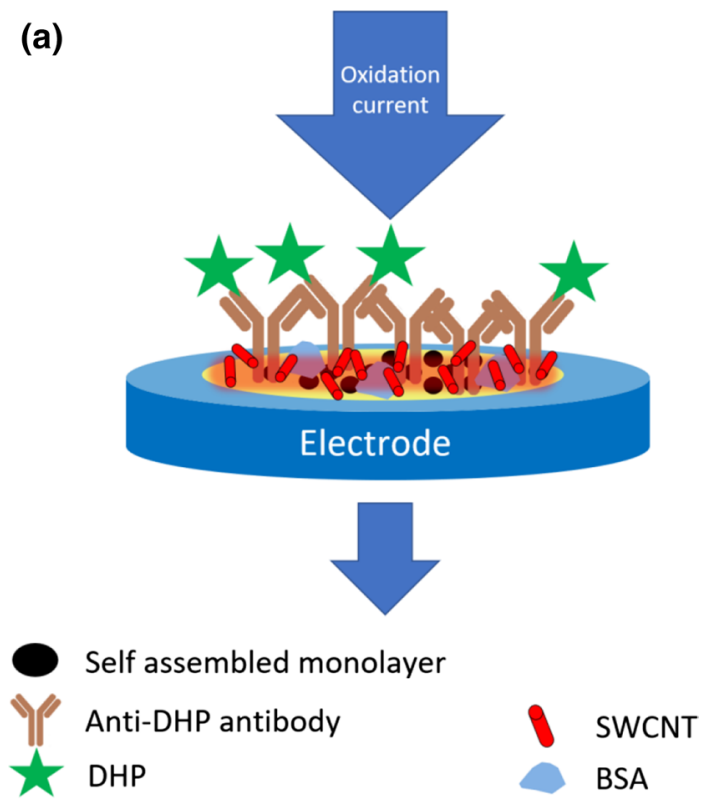

(b)

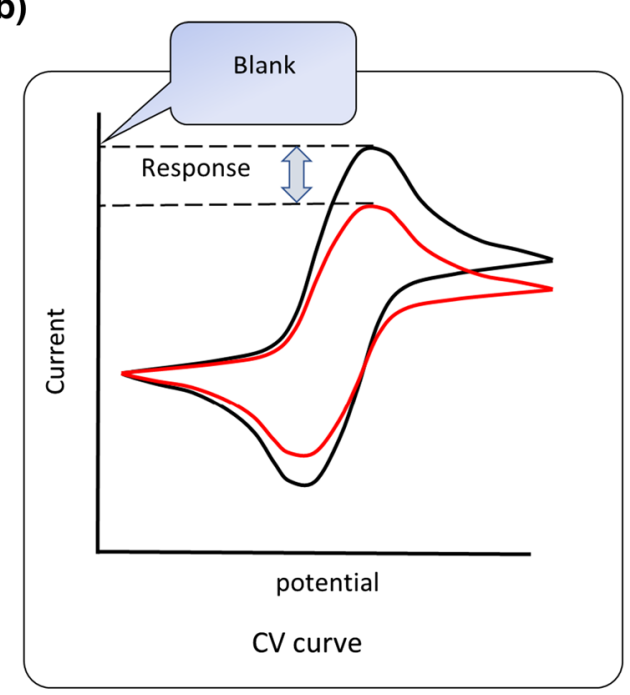

\section{Measurement principle (example)}

Fig. 9 Methodological basis of the 17,20ß-dihydroxy-4-pregnen-3one $(D H P)$ biosensor. a Decrease in the current as a result of oxidation due to the antibody-antigen complex, $\mathbf{b}$ response of the biosensor using cyclic voltammetry

electrode (working electrode) using CV. Because electron transfer between the electrode surface and the redox-active substance is inhibited by the antigen-antibody complex of DHP and the antibody, the oxidation current decreases as the DHP concentration increases. We attempted to quantify DHP using this system and found a good linear relationship between the current of the sensor output and the sensor in a concentration range of 7.8 to $500 \mathrm{pg} \mathrm{m}^{-1}$ (correlation coefficient: 0.9967). Next, for application to real samples, the DHP concentration in the plasma sample of mature fish (goldfish Carassius auratus) was measured and compared with the results obtained by the conventional method (ELISA). The correlation between the measurement methods was good. Because the amount of DHP in the blood before ovulation in actual fish varies from tens to hundreds of thousands picograms per milliliter, however, in the DHP measurement range $\left(7.8-\mathrm{pg} \mathrm{ml}^{-1}\right)$ of this system, dilution of the collected plasma samples was required before measurement.

To address this problem, we introduced a carbon nanotube (CNT) made of highly conductive material into the biosensor (Hirai et al. 2013). The CNT was developed by Iijima (1991), and has attracted a great deal of attention as a highly effective nanomaterial with various physical properties. Single-walled carbon nanotubes (SWCNTs) are highly conductive substances characterized by a variety of threedimensional structures, making conductivity easy to control. Therefore, by immobilizing SWCNT together with antiDHP antibody at the detection part of the above-mentioned biosensor, we attempted to expand the measurement of the dynamic range of DHP and increase the sensitivity of the sensor. A calibration curve was prepared using a DHP standard sample under this condition, and a good linear relationship (correlation coefficient 0.9827 ) was confirmed in the concentration range of 15.6 to $50,000 \mathrm{pg} \mathrm{ml}^{-1}$, a detection range 1000 times greater than the previous one. The developed sensor was applied to monitor DHP concentrations in goldfish plasma. The measurement time of the sensor, including the incubation time, is about $15 \mathrm{~min}$. Figure 10 shows the chronological changes of DHP concentrations in goldfish plasma measured by the proposed sensor and the conventional ELISA method. In the experiment described in each panel, maturation-inducing steroid was administered at $0 \mathrm{~h}$, and the measurement was performed every $3 \mathrm{~h}$. There was a good correlation between the results of both methods (proposed sensor system and ELISA). The maximum DHP concentration measured using our proposed sensor was $4.31-6.35 \mathrm{ng} \mathrm{ml}^{-1}$ and that by ELISA was 4.83-7.42 $\mathrm{ng} \mathrm{ml}^{-1}$. We confirmed that the DHP concentrations increased suddenly before ovulation. This biosensor system allows for the simple and rapid measurements of DHP. A rapid increase in the DHP concentration can be used to predict ovulation.

\section{Detection of harmful pathogens}

The detection of pathogenic bacteria that cause diseases in fish is also important in aquaculture. Detection methods such as FCM and PCR were developed for this, and enable 


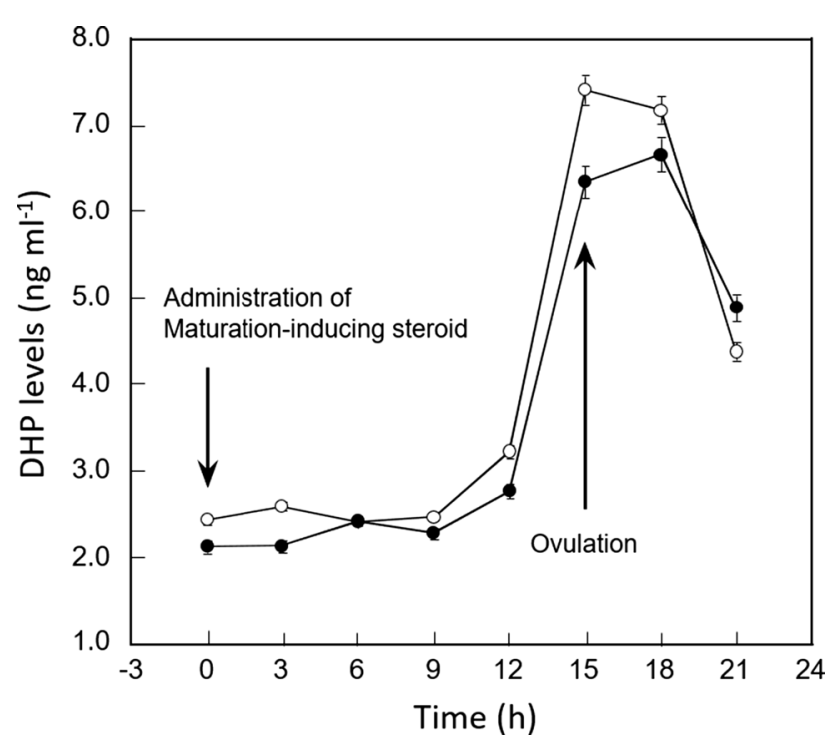

Fig. 10 Monitoring of DHP concentrations in plasma of test fish. Cyclic voltammetry was performed in $5 \mathrm{mM}$ potassium ferricyanide with $0.1 \mathrm{M}$ potassium chloride at a scan rate of $100 \mathrm{mV} \mathrm{s}^{-1}$. The voltage range was -0.2 to $+0.6 \mathrm{~V}$. Assay conditions were as follows: temperature $30{ }^{\circ} \mathrm{C}, \mathrm{pH} 6.5$, and incubation time $10 \mathrm{~min}$. Presented are results of the proposed sensor (filled circles) and results of the ELISA assay (open circles). Each sample was measured three times. Each data point presents the mean value and the error bars show the maximum and minimum values [Reproduced from Fig. 6, Hirai et al. (2013) Carbon nanotube enhanced label-free immunosensor for amperometric determination of oocyte maturation-inducing hormone in fish. Fish Physiol Biochem 39:299-308]
However, when the number of bacterial cells in the sample is extremely low, the probability of detection is also low. Also, the presence of a number of contaminants in the sample may hinder the detection of bacteria.

Highly sensitive measurement of bacteria can be realized by efficiently separating and concentrating the target bacterial cells in a sample. A highly sensitive magnetic separation method to concentrate microorganisms in fish samples, immunomagnetic separation, was developed several years ago (Hibi et al. 2006). We combined this method with FCM and achieved acceptable detection results (Hibi et al. 2007, 2008, 2012a). To further increase the detection limit, we introduced high gradient immunomagnetic separation (HGIMS) (Ryumae et al. 2010).

HGIMS is based on the use of a thin metal magnetic material such as a stainless-steel wire, which is used as a filter, and increases the magnetic field gradient by magnetizing it, efficiently concentrating bacteria (Ryumae et al. 2010, 2012). Figure 11 shows an outline of the HGIMS system for detecting cold water pathogenic bacteria (Flavobacterium psychrophilum) in ayu. First, in the immune reaction tank, F. psychrophilum cells in the sample are reacted with immunomagnetic beads that specifically bind to them. F. psychrophilum cells bound to the magnetic immunomagnetic beads are then magnetically transferred to a separation reactor and trapped by HGIMS on the stainless-steel filter magnetized by the ring magnet. Other bacteria and non-biological particles
Fig. 11 Schematic diagram of the high gradient immunomagnetic separation system. 1 Immunomagnetic beads, 2 target bacteria, 3 buffer tank, 4 reaction vessel, 5 micro pump, 6 magnetic separation reactor, 7 ring magnet, 8 magnetic filter, 9 remaining sample tank, 10 waste tank [Modified from Fig. 1, Ryumae et al. (2010) Rapid and highly sensitive detection of Flavobacterium psychrophilum using high gradient immunomagnetic separation with flow cytometry. Aquaculture 309: 125-130]

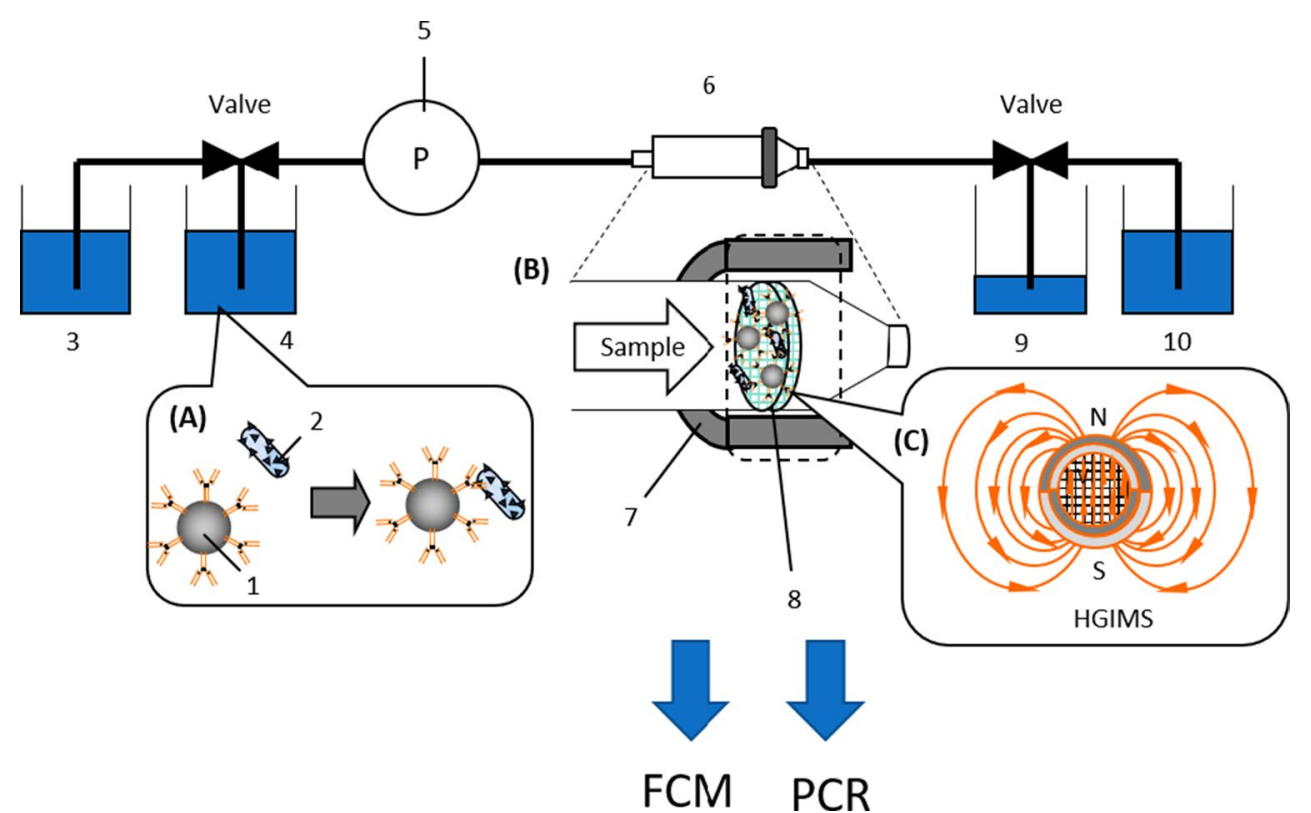

rapid and simple measurement of pathogenic bacteria (Chilmonczyk and Monge 1999; González et al. 2004). These are highly sensitive methods, and bacteria in water or soil samples can be detected in very small samples $(\sim 100 \mu \mathrm{l})$. pass through the magnetic filter to a waste liquid tank. The ring magnet is then removed to halt the magnetism, and target bacterial cells are collected from the filter in 
the sample tank within the buffer solution, for which the valve opening is adjusted. Because only concentrated target bacterial cells accumulate in the sample tank, the measurements are expected to be more sensitive than those achieved with commonly used FCM or PCR (Chilmonczyk and Monge 1999; González et al. 2004).

The HGIMS concentration method is characterized by a filter with a mesh diameter that can be increased. The conventional membrane filter typically used for bacteria has a mesh diameter smaller than that of the microorganism $(1-10 \mu \mathrm{m})$ that it physically traps and separates; bacterial cells can clog the mesh, thus high pressure is required for fluid transfer. In this method, the magnetic field gradient increases with the mesh diameter of the stainless-steel filter, and the magnetic force increases accordingly. Consequently, since the mesh size can be set to $100-500 \mu \mathrm{m}$, transfer at low pressure becomes possible, and clogging by the sample is also less likely to occur. Furthermore, because the immunomagnetic beads deposited on the filter can be separated by blocking the magnetic field, the bacterial cells can be easily released.

When attempting to detect $F$. psychrophilum using FCM by concentrating the bacterial cell sample according to the above-mentioned method, a good correlation was found between measured values for bacterial cell concentrations in the range of $10^{1}$ to $10^{5}$ colony-forming units (CFU) $\mathrm{ml}^{-1}$ (Ryumae et al. 2010). The time required for measurement by FCM was $1 \mathrm{~min}$, and it was possible to complete the measurement within $150 \mathrm{~min}$, including the time for sample pretreatment. By combining HGIMS and FCM in this way, extremely rapid measurement of $F$. psychrophilum is possible. When bacteria were concentrated using the HGIMS system and detected using PCR, the expected size band (346 base pairs) was in the range of $4 \times 10^{-1}$ to $4 \times 10^{3} \mathrm{CFU} \mathrm{ml}^{-1}$ (Ryumae et al. 2012). In other words, highly sensitive detection of $F$. psychrophilum at density of $10^{-1} \mathrm{CFU} \mathrm{ml} \mathrm{m}^{-1}$ could be realized. The time required for detection when using HGIMS/PCR method was about $3.5 \mathrm{~h}$, including the sample pretreatment time.

For F. psychrophilum measurement, the limit of detection of the conventional method without HGIMS is $10^{4} \mathrm{CFU} \mathrm{ml}{ }^{-1}$ with FCM and $10^{3} \mathrm{CFU} \mathrm{ml}^{-1}$ with PCR. Using our proposed HGIMS system, the detection sensitivity was improved 1000-fold for FCM and 10,000-fold for PCR. This system can efficiently concentrate bacterial cells in a sample containing contaminants such as those commonly seen in fish farms and rivers, and the concentrated sample can be applied to both FCM and PCR. For FCM, it is possible to perform rapid and quantitative measurements of the number of bacteria in only $1 \mathrm{~min}$; for PCR, extremely sensitive detection can be achieved with as few as $4 \times 10^{-1} \mathrm{CFU} \mathrm{ml}^{-1}$.

\section{Measurement of other important physiological indicators of fish health}

Many studies on fish physiology have used concentrations of blood plasma components to determine the condition of fish. For example, changes in the plasma whole cholesterol concentration were used to analyze the immunity, effect of toxins, metabolism, and sperm function in target fish (Maita et al. 1998a, b). Measurement of the whole cholesterol concentration is important as an indicator of the state, metabolism, and reproduction of fish; more indepth studies on whole cholesterol concentration might further improve aquaculture methods. L-Lactic acid is the final product of sugar metabolism and the glycolytic pathway caused by a reduction in pyruvic acid due to catalysis by lactic acid dehydrogenase. Blood L-lactic acid levels increase in fish exposed to transport stress (Hur et al. 2007), pesticides (Kamalaveni et al. 2003), and sublethal concentrations of waste residues from distillation processes (Ramakritinan et al. 2005).

We have developed FIA biosensor systems for these indicators similar to the glucose sensor developed using a corresponding enzyme several years ago (Endo et al. 2003, 2009b). At that point, some wireless biosensor systems for the determination of whole cholesterol concentration were developed (Yoneyama et al. 2009; Takase et al. 2014). We used a highly sensitive CNT to enhance sensor sensitivity for the real time monitoring of total cholesterol in free-swimming fish (Taogesi et al. 2015). The dynamic range matched the range of cholesterol concentrations in fish (50-300 mg dl${ }^{-1}$ ). Changes in total cholesterol concentration could be continuously monitored for $26 \mathrm{~h}$ in free-swimming fish using this sensor. We also developed a biosensor system to continuously monitor L-lactic acid concentrations in fish (Hibi et al. 2012b). EISF was used as the site of sensor implantation. The blood L-lactic acid concentrations correlated closely with the EISF L-lactic acid concentrations. Wireless monitoring of L-lactic acid was performed using the sensor in free-swimming fish. The sensor response was stable for over $60 \mathrm{~h}$. We believe that these sensors can be applied to studies of fish physiology to deepen our knowledge of fish cultivation, leading to improvements in aquaculture.

\section{Future studies}

In the process of conducting the above research, we received many requests from academics worldwide for the use of these developed biosensors for basic research on fish stress responses in university research laboratories 
and aquaria. These biosensor systems are very promising not only for use in fish farms but also for fish research conducted in laboratory-scale small water tanks. In a recent study, we aimed to construct a new biosensor system that can easily discriminate between stress responses in fish, even in seawater (Shinoda et al. 2017). Because seawater greatly attenuates radio waves, which our proposed transmitters use, the range of fish species that can be equipped with our biosensors system is limited. Also, to be able to assess stress responses using a more intuitive output, we developed a method of visual output to indicate the level of stress (Wu et al. 2019). Specifically, we constructed a biosensor capable of electrochemically measuring a change in the concentration of an electrode-active substance generated by an enzyme reaction on a substrate, such as glucose, using a light-emitting diode (LED) combined with optical communication technology to transmit information about the level of activity of the substance (Wu et al. 2019). In this system, green, for example, indicates that a fish is in a normal, unstressed state, yellow indicates a slightly increased level of stress, and red indicates a high level of stress.

The LED changed color according to the output voltage, confirmed by changing the EISF glucose concentration to $50 \mathrm{mg} \mathrm{dl}^{-1}, 100 \mathrm{mg} \mathrm{dl}^{-1}$ and $200 \mathrm{mg} \mathrm{dl}^{-1}$ (Fig. 12a). The results indicated that the sensor responded quickly to a change in the glucose concentration, with the LED color changing in real time according to this change. Thus, the LED controller can alter the LED color in accordance with the settings in vitro, i.e., the color-switching circuit of this system responded to the output current/voltage of the sensor and effectively provided a visual indication of the magnitude of the stress response.

We applied this system to Nile tilapia and attempted to visualize the stress response in vivo. Increasing the dissolved ammonia concentration in the breeding water as a stressor led to an increase of the output current/voltage of the sensor, confirming that the LED color changed based on the preset threshold values, as shown in Fig. 12b. In addition to quantitatively measuring the glucose level, a photoreceiver was attached near the surface of the water for optical communication with the LED. The glucose concentration measured by the sensor system strongly correlated with the blood glucose level measured using the conventional method. These results confirmed that the proposed biosensor system could monitor the stress response and visualize the stress level in freely swimming fish in real time, allowing investigators to evaluate fish stress. We also examined the sensor communication range in air and in water (fresh water or seawater), and found that it was possible to communicate within essentially the same range in air and in water, i.e., the system can be used not only in fresh water, but also within the seawater scale of salinity. Therefore, the system can be used
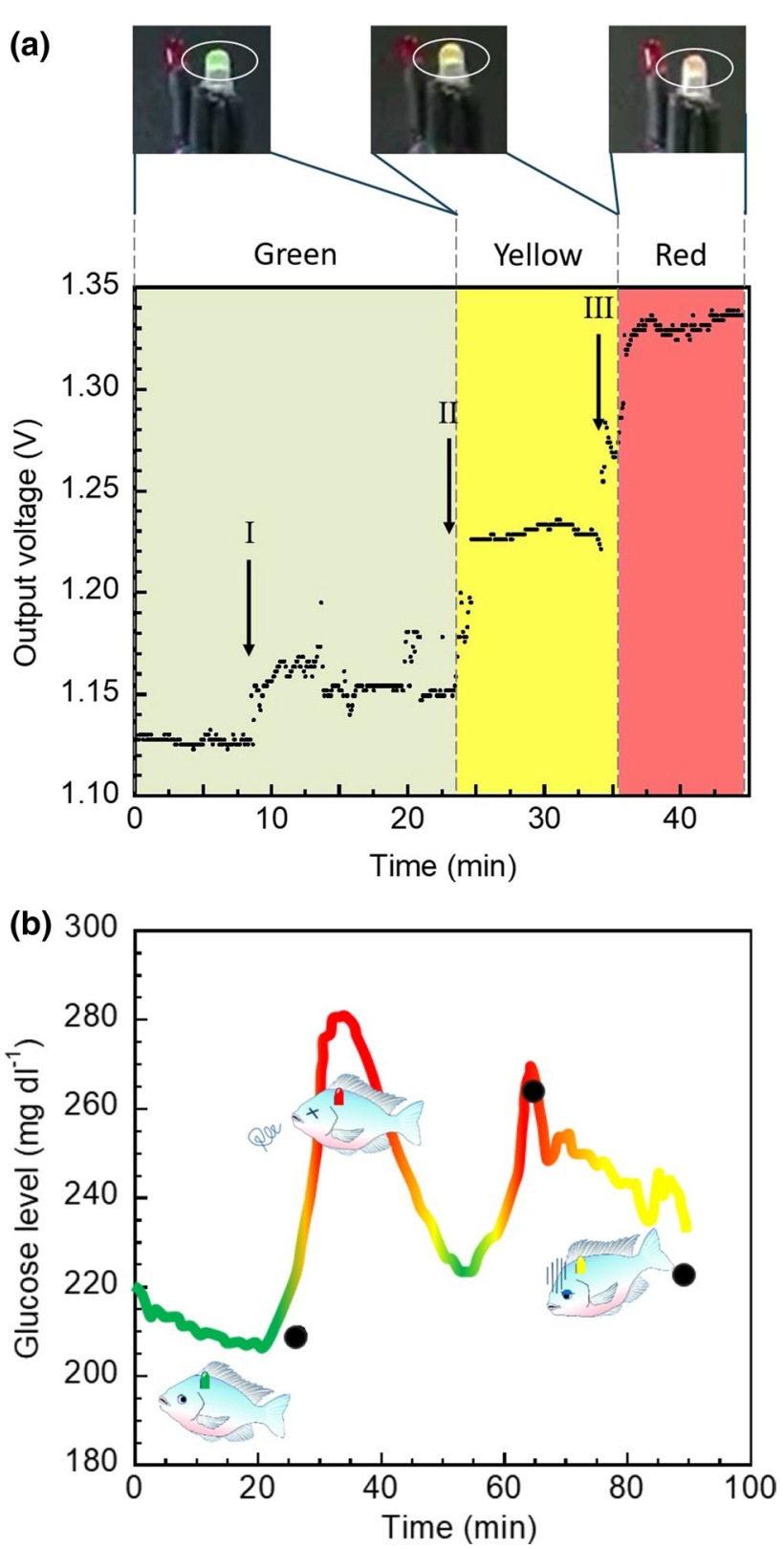

Fig. 12 Monitoring the glucose concentration by a light-emitting diode (LED) color-switching biosensor system. a Evaluation of LED color-switching system performance (in vitro). Arrows indicate the moment of addition of the glucose standard: $I 50 \mathrm{mg} \mathrm{dl}^{-1}, I I$ $100 \mathrm{mg} \mathrm{dl}^{-1}$, III $200 \mathrm{mg} \mathrm{dl}^{-1}$. b Monitoring the effects of a change in the concentration of the stressor, ammonia, from 0.25 to $25 \mathrm{mg} \mathrm{l}^{-1}$. Glucose concentrations in the blood plotted as black circles [Reproduced from Fig. 5, Wu et al. (2019) real time fish stress visualization come true: a novel multi-stage color-switching wireless biosensor system. Biosens Bioelectron 130: 360-366], [reproduced from Fig. 6b, Wu et al. (2019) Real time fish stress visualization come true: a novel multi-stage color-switching wireless biosensor system. Biosens Bioelectron 130: 360-366]

to monitor fish stress responses and aid the physiological research of fish, e.g. to monitor the effects of an overcrowded breeding environment on fish health. 
Our proposed biosensor system allows for real time monitoring of fish stress, and provides both numerical data and visualized results. Some limitations regards the applicability of the sensor, however, must be overcome. Currently, the system must be calibrated by manipulating the electronic circuit, and requires further simplification. In addition, it is not yet possible to identify the stress level of individual fish. To address these issues, our future research will focus on further improving the communication aspects and calibration of the method, and controlling the feedback from the electronic circuit using computer software instead of the transmitter itself, through new communications technology.

As discussed above, biosensors can be used for the evaluation of fish health. We believe that these techniques can be of great benefit to the aquaculture industry, as well as to some research fields, e.g., fish physiology and fish behavior. We will continue to work on miniaturization of the biosensor and enhancing its sensitivity and durability. We will also try to combine the described sensor with physical sensors, such as thermometers and accelerometers, and technologies like the Global Positioning System, to enable a better, more comprehensive assessment of fish health.

Acknowledgement Published with the support of the Japan Society for the Promotion of Science (JSPS) KAKENHI grant no. JP 262003.

Open Access This article is distributed under the terms of the Creative Commons Attribution 4.0 International License (http://creativeco mmons.org/licenses/by/4.0/), which permits unrestricted use, distribution, and reproduction in any medium, provided you give appropriate credit to the original author(s) and the source, provide a link to the Creative Commons license, and indicate if changes were made.

\section{References}

Anderson J (2002) Aquaculture and the future: why fisheries economists should care. Mar Resour Econ 17:133-151

Asche F, Tveterås S (2005) On the relationship between aquaculture and reduction fisheries. J Agric Res Ecol 55:245-265

Baquero F, Martínez J, Cantón R (2008) Antibiotics and antibiotic resistance in water environments. Curr Opin Biotechnol 19:260-265

Barton B (2000) salmonid fishes differ in their cortisol and glucose responses to handling and transport stress. N Am J Aquac 62:12-18

Bonga S (1997) The stress response in fish. Physiol Rev 77:591-625

Cabello F (2006) Heavy use of prophylactic antibiotics in aquaculture: a growing problem for human and animal health and for the environment. Environ Microbiol 8:1137-1144

Chilmonczyk S, Monge D (1999) Flow cytometry as a tool for assessment of the fish cellular immune response to pathogens. Fish Shellfish Immunol 9:319-333

Endo H, Maita M, Takikawa M, Ren H, Hayashi T, Urano N, Mitsubayashi K (2003) Enzyme sensor system for determination of total cholesterol in fish plasma. Fish Sci 69:1194-1199

Endo H, Yonemori Y, Musiya K, Maita M, Shibuya T, Ren H, Hayashi T, Mitsubayashi K (2006) A needle-type optical enzyme sensor system for determining glucose levels in fish blood. Anal Chim Acta 573-574:117-124

Endo H, Yonemori Y, Hibi K, Ren H, Hayashi T, Tsugawa W, Sode K (2009a) Wireless enzyme sensor system for real time monitoring of blood glucose levels in fish. Biosens Bioelecton 24:1417-1423

Endo H, Hao J, Maita M, Hayashi T, Ren H, Hibi K (2009b) Use of an optical biosensor with a silicone-immobilized enzyme to determine plasma total cholesterol concentrations in fish. Fish Sci 75:1329-1336

Endo H, Takahashi E, Murata M, Ohnuki H, Ren H, Tsugawa W, Sode K (2010) Wireless monitoring of blood glucose levels in flatfish with a needle biosensor. Fish Sci 76:687-694

Endo H, Muramatsu T, Yoshizaki G, Ren H, Ohnuki H (2012) Development of a label-free immunosensor system for detecting oocyte maturation-inducing hormone in fish. Fish Sci 78:391-398

Fletcher D (1984) Plasma glucose and plasma fatty acid levels of Limanda limanda (L.) in relation to season, stress, glucose loads and nutritional state. J Fish Biol 25:629-648

Frankic A, Hershner C (2003) Sustainable aquaculture: developing the promise of aquaculture. Aquac Int 11:517-530

Fromm P (1980) A review of some physiological and toxicological responses of freshwater fish to acid stress. Environ Biol Fishes 5:79-93

Gilmour K, DiBattista J, Thomas J (2005) Physiological causes and consequences of social status in salmonid fish. Integr Comp Biol 45:263-273

González F, Krug M, Nielsen M, Santos Y, Call D (2004) Simultaneous detection of marine fish pathogens by using multiplex PCR and a DNA microarray. J Clin Microbiol 42:1414-1419

Grieshaber D, MacKenzie R, Vörös J, Reimhult E (2008) Electrochemical biosensors-sensor principles and architectures. Sensors 8:1400-1458

Hibi K, Abe A, Ohashi E, Mitsubayashi K, Ushio H, Hayashi T, Ren $\mathrm{H}$, Endo H (2006) Combination of immunomagnetic separation with flow cytometry for detection of Listeria monocytogenes. Anal Chim Acta 573-574:158-163

Hibi K, Mitsubayashi K, Fukuda H, Ushio H, Hayashi T, Ren H, Endo H (2007) Rapid direct determination using combined separation by prepared immunomagnetic and flow cytometry of Flavobacterium psychrophilum. Biosens Bioelecton 22:1916-1919

Hibi K, Ushio H, Fukuda H, Mitsubayashi K, Hayashi T, Ren H, Endo H (2008) Immunomagnetic separation using carbonyl iron powder and flow cytometry for rapid detection of Flavobacterium psychrophilum. Anal Bioanal Chem 391:1147-1152

Hibi K, Yoshiura Y, Ushio H, Ren H, Endo H (2012a) Rapid detection of Flavobacterium psychrophilum using fluorescent magnetic beads and flow cytometry. Sens Mater 24:311-322

Hibi K, Hatanaka K, Takase M, Ren H, Endo H (2012b) Wireless biosensor system for real time L-lactic acid monitoring in fish. Sensors 12:6269-6281

Hirai M, Muramatsu T, Ohnuki H, Hibi K, Ren H, Endo H (2013) Carbon nanotube enhanced label-free immunosensor for amperometric determination of oocyte maturation-inducing hormone in fish. Fish Physiol Biochem 39:299-308

Hur J, Park I, Chang Y (2007) Physiological responses of the olive flounder, Paralichthys olivaceus, to a series stress during the transportation process. Ichthyol Res 54:32-37

Iijima S (1991) Helical microtubules of graphitic carbon. Nature 354:56-58

Inoue $\mathrm{K}$, Wada M, Higuchi T, Oshio S, Umeda T, Yoshimura Y, Nakazawa $H$ (2002) Application of liquid chromatography-mass spectrometry to the quantification of bisphenol A in human semen. $\mathrm{J}$ Chromatogr B 773:97-102 
Irianto A, Austin B (2002) Probiotics in aquaculture. J Fish Dis 25:633-642

Kamalaveni K, Gopal V, Sampson U, Aruna D (2003) Recycling and utilization of metabolic wastes for energy production is an index of biochemical adaptation of fish under environmental pollution stress. Environ Monit Assess 86:255-264

Lewis W Jr, Morris D (1986) Toxicity of nitrite to fish: a review. Trans Am Fish Soc 115:183-195

Lou SW, Aida K, Hanyu I, Sakai K, Nomura M, Tanaka M, Tazaki S (1984) Endocrine profiles in the females of a twice-annually spawning strain of rainbow trout. Aquaculture 43:13-22

Lowe T, Ryder J, Carragher J, Wells R (1993) Flesh quality in snapper, Pagrcrs auratus, affected by capture stress. J Food Sci 58:770-773

Maita M, Aoki H, Yamagata Y, Satoh S, Okamoto N, Watanabe T (1998a) Plasma biochemistry and disease resistance in yellowtail fed a nonfish meal diet. Fish Pathol 33:59-63

Maita M, Satoh K, Fukuda Y, Lee H, Winton J, Okamoto N (1998b) Correlation between plasma component levels of cultured fish and resistance to bacterial infection. Fish Pathol 33:129-133

Matsuyama M, Adachi S, Nagahama Y, Kitajima C, Matsuura S (1991) Annual reproductive cycle of the captive female Japanese sardine Sardinops melanostictus: relationship to ovarian development and serum levels of gonadal steroid hormones. Mar Biol 108:21-29

Mazeaud M, Mazeaud F, Donaldson M (1977) Primary and secondary effects of stress in fish: some new data with a general review. Trans Am Fish Soc 106:201-212

Muramatsu T, Ohnuki H, Ushio H, Hibi K, Igarashi M, Hayashi T, Ren H, Endo H (2011) Electrochemical flow injection immunoassay for cortisol using magnetic microbeads. Int J Environ Anal Chem 91:161-173

Naylor R, Goldburg R, Primavera J, Kautsky N, Beveridge M, Clay J, Lubchenco J, Mooney H, Troell M (2000) Effect of aquaculture on world fish supplies. Nature 405:1017-1024

Pickering A, Pottinger T (1989a) Stress responses and disease resistance in salmonid fish: effects of chronic elevation of plasma cortisol. Fish Physiol Biochem 7:253-258

Pickering A, Pottinger T (1989b) Stress responses and disease resistance in salmonid fish: effects of chronic elevation of plasma cortisol. Fish Physiol Biochem 7:253-258

Pottinger T, Carrick T (2001) A comparison of plasma glucose and plasma cortisol as selection markers for high and low stress-responsiveness in female rainbow trout. Aquaculture 175:351-363

Ramakritinan C, Kumaraguru A, Balasubramanian M (2005) Impact of distillery effluent on carbohydrate metabolism of freshwater fish, Cyprinus carpio. Ecotoxicology 14:693-707

Rotllant J, Tort L (1997) Cortisol and glucose responses after acute stress by net handling in the sparid red porgy previously subjected to crowding stress. J Fish Biol 51:21-28

Ryumae U, Hibi K, Yoshiura Y, Ren H, Endo H (2010) Rapid and highly sensitive detection of Flavobacterium psychrophilum using high gradient immunomagnetic separation with flow cytometry. Aquaculture 309:125-130

Ryumae U, Hibi K, Yoshiura Y, Ren H, Endo H (2012) Ultra highly sensitive method for detecting Flavobacterium psychrophilum using high-gradient immunomagnetic separation with polymerase chain reaction. Aquac Res 43:929-939

Shinoda R, Wu H, Murata M, Ohnuki H, Yoshiura Y, Endo H (2017) Development of an optical communication type biosensor for real time monitoring of fish stress. Sens Actuator B Chem 247:765-773

Silbergeld E (1974) Blood glucose: a sensitive indicator of environmental stress in fish. Bull Environ Contam Toxicol 11:20-25

Stacey N, Sorensen P, Kraak G, Dulka J (1989) Direct evidence that $17 \alpha, 20 \beta$-dihydroxy-4-pregnen-3-one functions as a goldfish primer pheromone: preovulatory release is closely associated with male endocrine responses. Gen Comp Endocrinol 75:62-70
Stagey N, Cook A, Peter R (1979) Spontaneous and gonadotropininduced ovulation in the goldfish, Carassius auratus L: effects of external factors. J Fish Biol 15:349-361

Stentiford G, Neil D, Peeler E, Shields J, Small H, Flegel T, Vlak J, Jones B, Morado F, Moss S, Lotz J, Bartholomay L, Behringer D, Hauton C, Lightner D (2012) Disease will limit future food supply from the global crustacean fishery and aquaculture sectors. J Invertebr Pathol 110:141-157

Takase M, Yoneyama Y, Murata M, Hibi K, Ren H, Endo H (2012a) Carbon nanotube enhanced mediator-type biosensor for real time monitoring of glucose concentrations in fish. Anal Bioanal Chem 403:1187-1190

Takase M, Yoneyama Y, Murata M, Hibi K, Ren H, Endo H (2012b) Mediator-type biosensor for real time wireless monitoring of blood glucose concentrations in fish. Fish Sci 78:691-698

Takase M, Takahashi E, Murata M, Ohnuki H, Hibi H, Ren H, Endo H (2013) Development of a biocompatible glucose biosensor for wireless and real time blood glucose monitoring of fish. Int J Environ Anal Chem 93:125-139

Takase M, Murata M, Hibi K, Huifeng R, Endo H (2014) Development of mediator-type biosensor to wirelessly monitor whole cholesterol concentration in fish. Fish Physiol Biochem 40:385-394

Taogesi WuH, Murata M, Ren H, Endo H (2015) Carbon nanotubeenhanced enzyme sensor for real time monitoring of cholesterol levels in free-swimming fish. Sens Mater 27:805-815

Tschmelak J, Proll G, Gauglitz G (2004) Verification of performance with the automated direct optical TIRF immunosensor (river analyser) in single and multi-analyte assays with real water samples. Biosens Bioelectron 20:743-772

Wells R, Pankhurst N (1999) Evaluation of simple instruments for the measurement of blood glucose and lactate, and plasma protein as stress indicators in fish. J World Aquac Soc 30:276-284

Windmiller J, Wang J (2013) Wearable electrochemical sensors and biosensors: a review. Electroanalysis 25:29-46

Wu H, Ohnuki H, Ren H, Endo H (2015a) Carbon nanotube-enhanced label-free immunosensor for highly sensitive detection of plasma cortisol levels in fish. Sens Mater 27:793-803

Wu H, Aoki A, Arimoto T, Nakano T, Ohnuki H, Murata M, Ren H, Endo H (2015b) Fish stress become visible: a new attempt to use biosensor for real time monitoring fish stress. Biosens Bioelecton 67:503-510

Wu H, Ohnuki H, Hibi K, Ren H, Endo H (2016) Development of a labelfree immunosensor system for detecting plasma cortisol levels in fish. Fish Physiol Biochem 42:19-27

Wu H, Ohnuki H, Murata M, Endo H (2017a) Flow immunosensor system with an electrode replacement unit for continuous cortisol monitoring for fish. Sens BioSens Res 13:122-127

Wu H, Ohnuki H, Ota S, Murata M, Yoshiura Y, Endo H (2017b) New approach for monitoring fish stress: a novel enzyme-functionalized label-free immunosensor system for detecting cortisol levels in fish. Biosens Bioelecton 93:57-64

Wu H, Shinoda R, Murata M, Matsumoto H, Ohnuki H, Endo H (2019) Real-time fish stress visualization came true:a novel multi-stage color-switching wireless biosensor system. Biosens Bioelectron 130:360-366

Yogeswaran U, Chen S (2008) A review on the electrochemical sensors and biosensors composed of nanowires as sensing material. Sensors 8:290-313

Yonemori Y, Takahashi E, Ren H, Hayashi T, Endo H (2009) Biosensor system for continuous glucose monitoring in fish. Anal Chim Acta 633:90-96

Yoneyama Y, Yonemori Y, Murata M, Ohnuki H, Hibi K, Hayashi T, Ren H, Endo H (2009) Wireless biosensor system for real-time cholesterol monitoring in fish "Nile tilapia". Talanta 80:909-915

Young G, Grim LW, Kagawa H, Kambegawa A, Nagahama Y (1983) Plasma 17 $\alpha, 20 \beta$-dihydroxy-4-pregnen-3-one levels during sexual maturation of amago salmon (Oncorhynchus rhodurus): correlation 
with plasma gonadotropin and in vitro production by ovarian follicles. Gen Comp Endocrinol 51:96-105

Zeilinger J, Steger-Hartmann T, Maser E, Goller S, Vonk R, Länge R (2009) Effects of synthetic gestagens on fish reproduction. Environ Toxicol Chem 28:2663-2670
Publisher's Note Springer Nature remains neutral with regard to jurisdictional claims in published maps and institutional affiliations. 